\title{
Nanostructured solar irradiation control materials for solar energy conversion
}

J. H. Kang ${ }^{\mathrm{a},{ }^{*}}$, I. A. Marshall ${ }^{\mathrm{b}}$, M. N. Torrico ${ }^{\mathrm{c}}$, C. R. Taylor ${ }^{\mathrm{d}}$, Jeffry Ely ${ }^{\mathrm{e}}$, Angel Z. Henderson ${ }^{\mathrm{e}}$, J.-W. Kim $^{\mathrm{a}}$, G. Sauti ${ }^{\mathrm{a}}$, L. J. Gibbons ${ }^{\mathrm{a}, \mathrm{f}}$, C. Park ${ }^{\mathrm{a}, \mathrm{g}}$, S. E. Lowther ${ }^{\mathrm{h}}$, P. T. Lillehei ${ }^{\mathrm{h}}$, and R. G. Bryant ${ }^{\mathrm{h}}$ ${ }^{\mathrm{a}}$ National Institute of Aerospace, Hampton, VA 23681, ${ }^{\mathrm{b}}$ University of South Dakota, SD 57069, ${ }^{c}$ University of Tennessee, TN 37996, ${ }^{d}$ University of Nebraska - Lincoln, Lincoln, NE 68508, ${ }^{\mathrm{e}}$ Old Dominion University, Norfolk, VA 23508, ${ }^{\mathrm{f}}$ Virginia Polytechnic Institute and State University, Blacksburg, VA 24061, ${ }^{\mathrm{g}}$ University of Virginia, Charlottesville, Department of Mechanical and Aerospace Engineering, VA 22903, hadvanced Materials and Processing Branch, NASA-Langley Research Center, Hampton, VA 23681-2199

\begin{abstract}
Tailoring the solar absorptivity $\left(\alpha_{S}\right)$ and thermal emissivity $\left(\varepsilon_{T}\right)$ of materials constitutes an innovative approach to solar energy control and energy conversion. Numerous ceramic and metallic materials are currently available for solar absorbance/thermal emittance control. However, conventional metal oxides and dielectric/metal/dielectric multi-coatings have limited utility due to residual shear stresses resulting from the different coefficient of thermal expansion of the layered materials. This research presents an alternate approach based on nanoparticle-filled polymers to afford mechanically durable solar-absorptive and thermally-emissive polymer nanocomposites. The $\alpha_{s}$ and $\varepsilon_{T}$ were measured with various nano inclusions, such as carbon nanophase particles (CNPs), at different concentrations. Research has shown that adding only $5 \mathrm{wt} \%$ CNPs increased the $\alpha_{s}$ and $\varepsilon_{T}$ by a factor of about 47 and 2, respectively, compared to the pristine polymer. The effect of solar irradiation control of the nanocomposite on solar energy conversion was studied. The solar irradiation control coatings increased the power generation of solar thermoelectric cells by more than $380 \%$ compared to that of a control power cell without solar irradiation control coatings.
\end{abstract}

Keywords: solar irradiation, solar energy, solar absorptivity, thermal emissivity, carbon nanophase paricles, composite

\section{INTRODUCTION}

Over the past few decades, solar energy has attracted renewed attention because it is a clean and sustainable energy resource, and it is also widely utilized as a power source in space exploration. There are two feasible approaches in utilizing solar energy, photo-electrical (photovoltaic) and thermoelectric (TE) conversion [1,2]. In order to maximize the solar power conversion efficiency, development of efficient solar absorption and thermal emission coating have been critical issues. There are substantial publications covering various types of solar absorbance coatings such as copper-chromium oxide $\left(\mathrm{CuCrO}_{\mathrm{x}}\right)$ or iron-manganese-copper oxide $\left(\mathrm{MFeMnCuO}_{\mathrm{x}}\right)$ in a silicone binder, transparent metal coatings of copper and silver, wide band gap semiconductors of tin oxide $\left(\mathrm{SnO}_{2}\right)$, indium tin oxide (ITO), and zinc oxide $(\mathrm{ZnO})$, plus multilayer coatings to create dielectric/metal/dielectric structures [3-5], which typically show high solar absorptivity $\left(\alpha_{s}>0.9\right)$ and low thermal emissivity $\left(\varepsilon_{T}<0.2\right)$. In addition, carbon based materials (graphite, $\varepsilon_{T}=0.98$ ), and 
cerium $\left(\varepsilon_{T}=0.90\right)$, copper $\left(\varepsilon_{T}=0.88\right)$, and iron $\left(\varepsilon_{T}=0.74\right)$ oxides are well known as high thermal emissivity materials [6].

Conventional metal oxides for solar absorption/thermal emission coatings possess poor mechanical properties (brittle) and are too heavy for many applications including deployable solar power panels. The multilayer coatings of the dielectric/metal/dielectric structure also have disadvantages associated with the delamination of the layers, high residual stress resulting from dissimilar thermal expansion coefficients of the layers and a complicated fabrication process. The first two problems are exacerbated in application environments where the coatings undergo repeated thermal cycling and can greatly limit the lifetimes of the coatings.

Polyurethane (PU) is widely used for various applications because of its unique properties of excellent flexibility, elasticity and durability. It is employed as an excellent matrix for composites because the properties are easily tailored by modifying its molecular structures of soft segments and hard segments [7]. Furthermore, it is a widely used inexpensive commercially available polymer.

Carbon nanophase particles (CNPs) or carbonaceous nanomaterials have been used as a filler in composite matrix to modify the mechanical, thermal, and electrical properties owing to the fascinating physical properties [7,8]. It is well known that the addition of small amount of CNPs enhances the mechanical properties of the composite for structural applications like aircraft brakes, aerospace structures and industrial concrete structures [9]. In addition, due to delocalization of $\pi$ electrons, CNPs present unique reflectance, absorbance, and transmittance properties against electromagnetic waves. CNPs exhibit uniquely high $\alpha_{s}$ and $\varepsilon_{T}$ accordingly $[9,10]$.

To overcome the problems of ceramic and metal oxide coatings, the $\alpha_{S} / \varepsilon_{T}$ of nanocomposites were controlled using CNPs embedded in PU, and the effect of this nanostructured material on the performance of energy harvesting of thermoelectric solar cells was studied.

\section{EXPERIMENTAL}

\subsection{Sample preparation}

$\mathrm{CNP} / \mathrm{PU}$ composites were prepared by direct mixing under simultaneous sonication and mechanical shear. PU was purchased in pellet form from Lubrizol Corporation (Eastane 5708, USA) and used as received. The PU pellets were dissolved in tetrahydrofuran (THF, Aldrich, USA) to make a PU solution $(20 \% \mathrm{w} / \mathrm{w})$. Carbon nanophase particles (\#N991, Surface area $\left(\mathrm{N}_{2}\right): 7-12 \mathrm{~m}^{2} / \mathrm{g}$, Cancarb Limited, Canada) were added into the prepared PU solution and vigorously stirred under sonication. The concentration of CNP in PU varied from $0 \mathrm{wt} \%$ to $50 \mathrm{wt} \%$. Thin films with a uniform thickness of about $30 \mu \mathrm{m}$ film were solution cast on a glass plate using a doctor blade. Metal oxides/PU and aluminum doped zinc oxide nanoparticles (\#677450, 6wt\% Al doped, Aldrich)/PU composite samples were prepared by a similar method.

\subsection{Characterization}

Crystalline structure of the nanocomposites was studied using an X-ray diffractormeter (D5000, Siemens Bruker AXS Analytical X-ray Systems GmBH, Germany). Wide angle X-ray diffraction (WXRD) patterns were collected with $\operatorname{CuK} \alpha(\lambda=1.5406 \AA)$ radiation in the range of $2 \theta=10-60^{\circ}$ 
and a step of $0.05^{\circ} . \alpha_{s}$ was measured with an AZTech LPSR 300 that measured the reflectivity of specific wavelengths from $250 \mathrm{~nm}$ to $2800 \mathrm{~nm}$. $\varepsilon_{\mathrm{T}}$ was measured with an AZTech TEMP 2000A that measured the reflectivity of the object for the $300 \mathrm{~K}$ black body spectrum ( $3 \mathrm{um}$ to $>35 \mathrm{um}$ ). $\alpha_{s}$ and $\varepsilon_{T}$ were then calculated after finding reflectivity and transmissivity.

The performance of a thermoelectric solar power cell with solar irradiation coatings was evaluated using a solar simulator (Oriel 3A solar simulator, Model 94043A, Newport, USA). The commercial thermoelectric cell (Model 12711, $\mathrm{Bi}_{2} \mathrm{Te}_{3}$ based thermoelectric, Custom Thermoelectric, USA) was placed on a black color coated empty box which was cooled by a circulator at $0^{\circ} \mathrm{C}$. Solar simulation of 1 Sun power with the AM-1.5 G filter simulates the annual average solar radiance over every US state except Alaska (Figure 1). Voltage, current and device temperature measurements were made using digital multimeters (Keithley 2000, Keithley 2700 and Keithley 2701) and a custom designed LabVIEW based program. Current was measured with a load (resistor) matching the device internal resistance to match the maximum power condition.
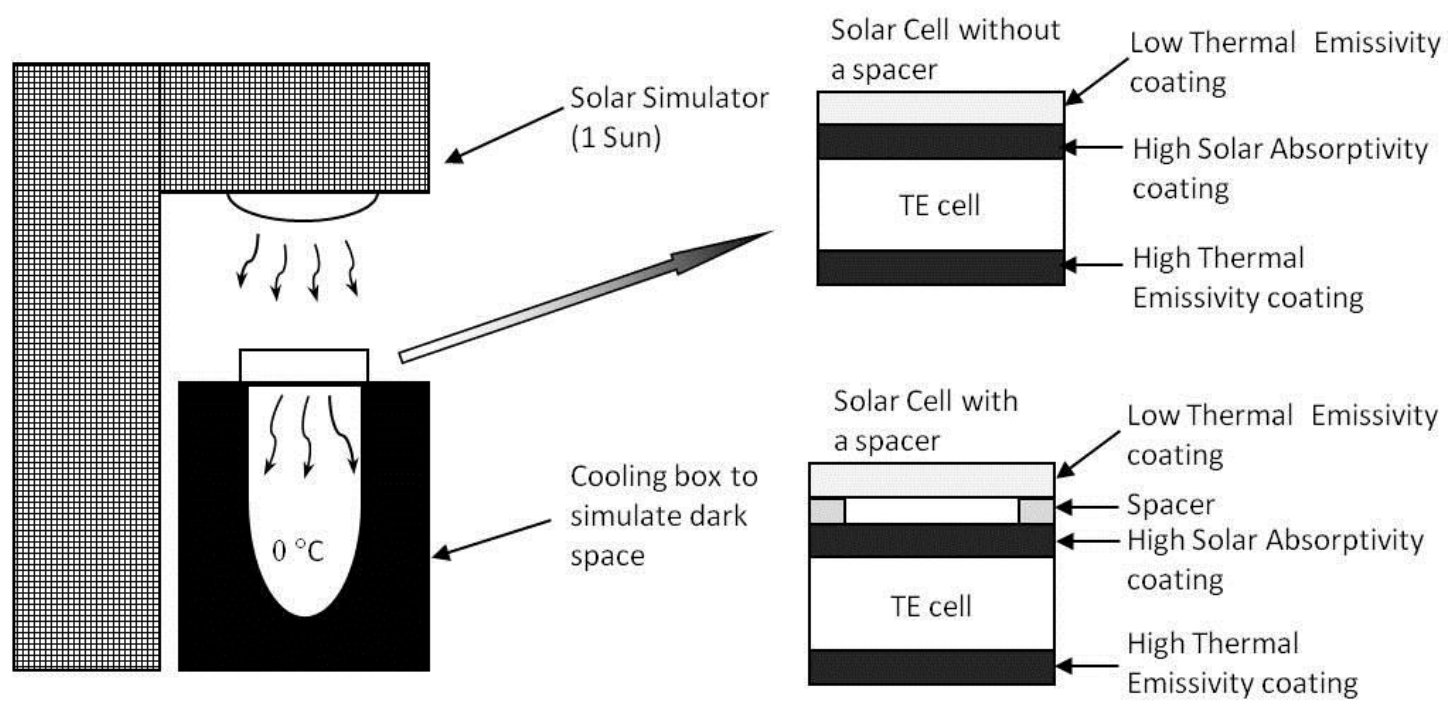

Figure 1. Experimental set up for measuring solar power generation and structure of test solar cell.

\section{RESULTS AND DISCUSSION}

WXRD peaks of pristine PU and $50 \mathrm{wt} \% \mathrm{CNP} / \mathrm{PU}$ composite are shown in Figure 2. Pristine PU shows a crystalline peak at $2 \theta$ of $21^{\circ}$, and broad amorphous halo at $2 \theta$ of $31^{\circ}$ [11]. With the addition of CNP into the PU matrix, the crystalline peak of PU at $21^{\circ}$ was decreased because CNP seems to hinder the crystallization of PU molecules, and the new peaks for CNP appeared at $25^{\circ}$ and $44^{\circ}$. This presents graphite-like quasi-crystalline domains [12]. 
(a)

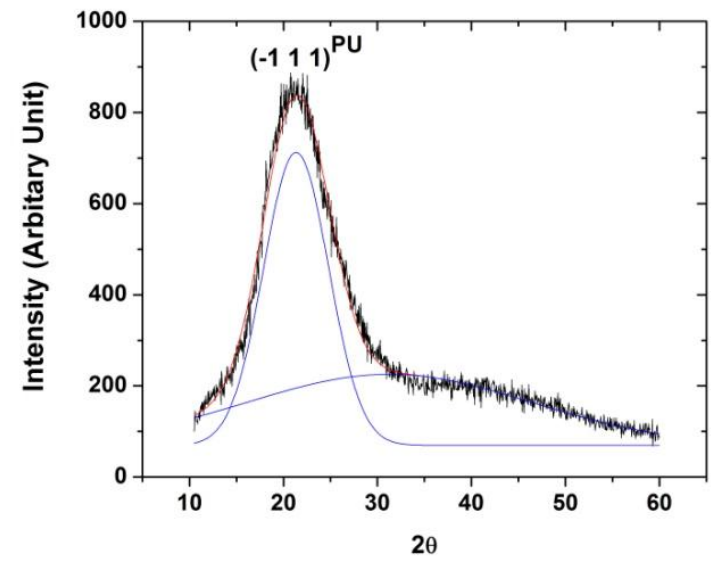

(b)

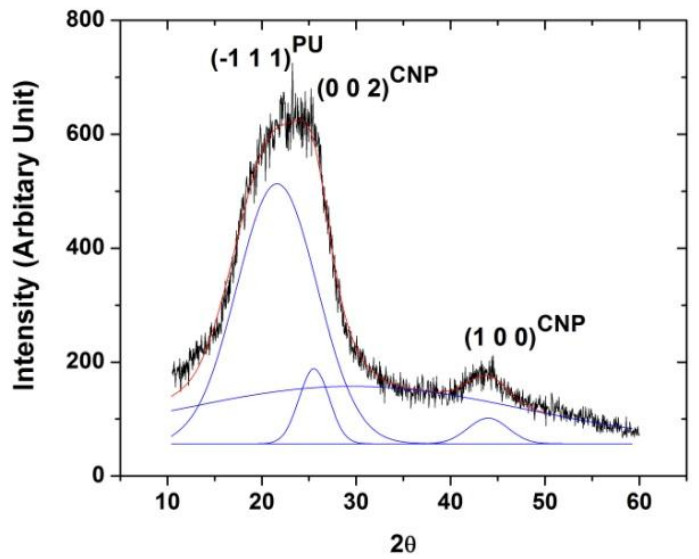

Figure 2. XRD patterns of (a) pristine PU and (b) $50 \mathrm{wt} \% \mathrm{CNP} / \mathrm{PU}$ composite.

Figure 3 (a) shows the $\alpha_{s}$ of CNP/PU composite films. The films were cast on a glass plate, both air and glass sides of film were investigated to see if there was any difference due to the substrate effect. No noticeable difference was found for each side over the range of CNP concentrations. The $\alpha_{s}$ of pristine PU was only 0.02, and increased with increasing CNP concentration until leveling out above $2 \mathrm{wt} \% \mathrm{CNP}$. The maximum $\alpha_{s}$ of 0.94 was reached with 5 wt $\%$ CNP incorporation. Above $5 \mathrm{wt} \%$, the $\alpha_{s}$ slightly decreased with increasing CNP concentration. This was mainly caused by a decrease in solar transmissivity although reflectance did slightly increase with increasing CNP concentration as shown in equation 1 :

$$
\alpha_{S}=1-\rho_{S}-\tau_{S}
$$

where $\alpha_{S}=$ solar absorptivity, $\rho_{S}=$ solar reflectivity, and $\tau_{S}=$ solar transmissivity.

The $\varepsilon_{T}$ of the CNP/PU composites as a function of CNP concentration is presented in Figure 3 (b). The $\varepsilon_{T}$ showed a similar trend to the $\alpha_{s}$ with increasing CNP concentration. The $\varepsilon_{T}$ of pristine PU was 0.45 , and increased very rapidly with increasing CNP concentration up to 5 wt $\%$. The maximum $\varepsilon_{T}$ of $\mathrm{PU}$ composite with $5 \mathrm{wt} \% \mathrm{CNP}$ incorporation was 0.93 . Above $5 \mathrm{wt} \%$, the $\varepsilon_{T}$ decreased with increasing CNP concentration. The $\varepsilon_{T}$ of PU composite with 50 wt $\% \mathrm{CNP}$ incorporation was 0.86 . The decrease seems to be caused by an increase in thermal reflectance from the graphite-like quasi-crystalline domains while thermal transmission decreased to nearly zero at 2 wt \% CNP as shown in equation $2[9,10]$ :

$$
\varepsilon_{T}=1-\rho_{T}-\tau_{T}
$$

where $\varepsilon_{T}=$ thermal emissivity, $\rho_{T}=$ thermal reflectivity, and $\tau_{T}=$ thermal transmissivity. 
(a)

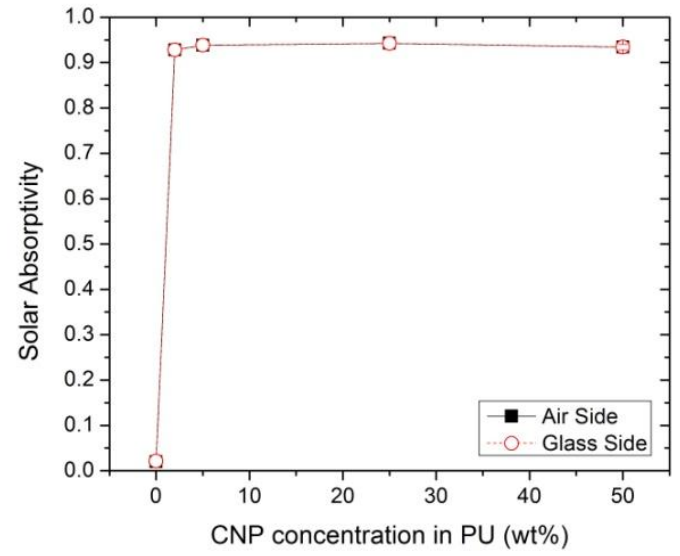

(b)

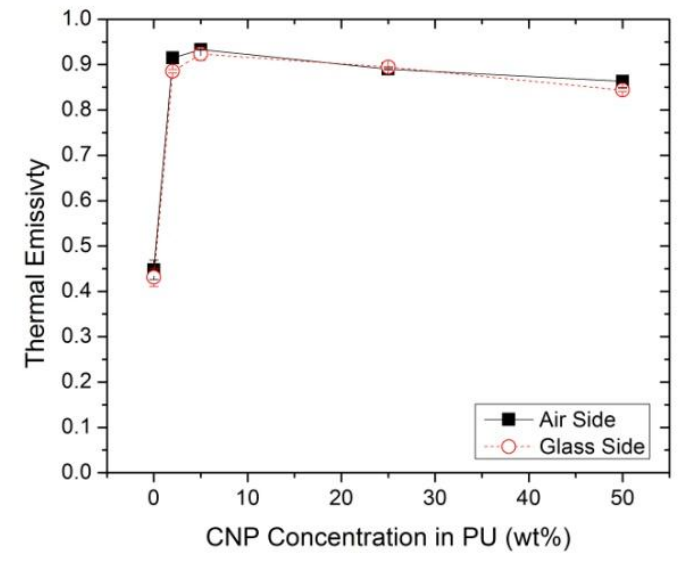

Figure 3. (a) Solar absorptivity and (b)thermal emissivity of CNP/PU composites.

The dispersion of CNP in the PU matrix was examined by a scanning electron microscope (SEM). The CNP size is about 300 to $700 \mathrm{~nm}$ (inset of Figure 4 (a)) and CNPs were homogenously dispersed throughout the PU matrix as shown in Figure 4 (a). The PU composite with 50 wt\% CNP was very flexible and stretchable as shown in Figure 4 (b), which may be an attractive material for deployable space structures.
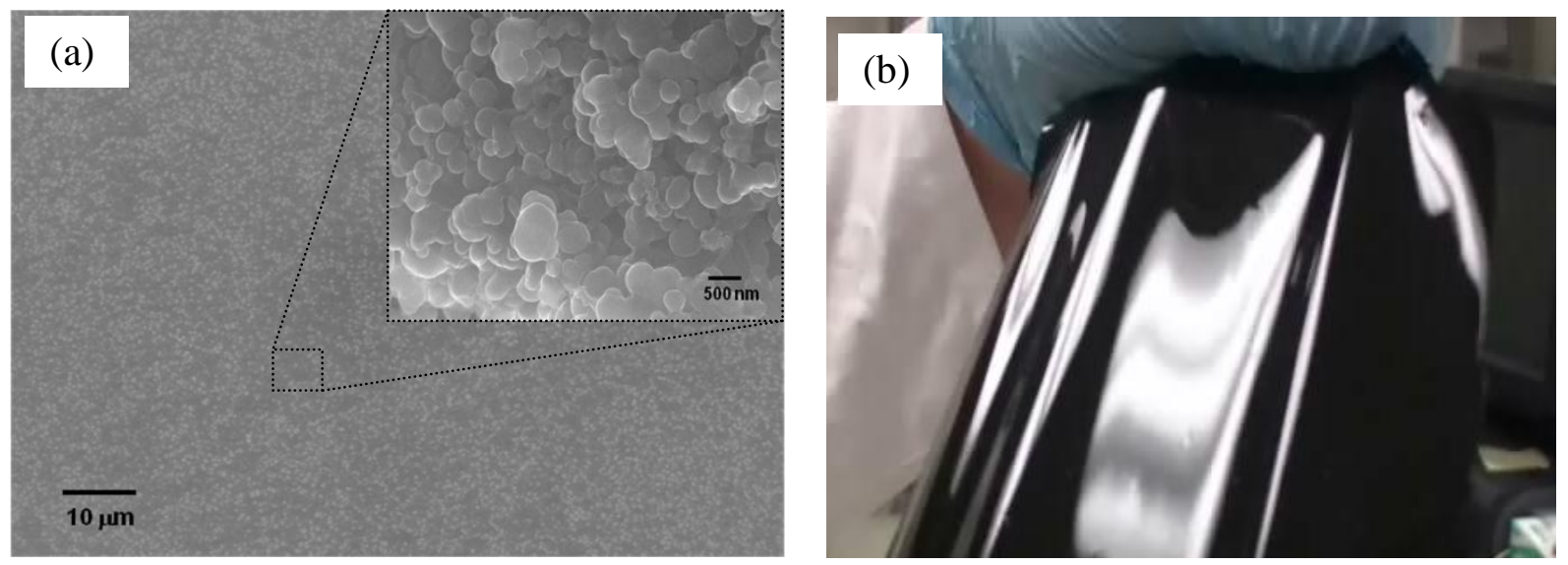

Figure 4. (a) SEM image and (b) visual image of $50 \mathrm{wt} \%$ CNP/PU composite.

The effect of the $\alpha_{s}$ and $\varepsilon_{T}$ layers on solar energy conversion for a thermoelectric solar power cell was studied. Figure 5 (a) shows the power generation of the control thermoelectric cell without any coating. When the light is turned on, the voltage and current started to increase and reached a plateau. The voltage and current decreased after switching the light off. The calculated power (W) followed the same trend as the generated voltage and current, and its maximum value was about $0.057 \mathrm{~mW}$. 
With the high $\varepsilon_{T}$ layer (5wt\% CNP/PU composite) on the bottom of the thermoelectric solar cell, the generated voltage and current increased (Figure 5 (b)). The resulting power is $0.104 \mathrm{~mW}$, showing about $82 \%$ increase compared to the control cell. The high $\varepsilon_{T}$ layer helps to reradiate thermal heat to dark space to generate more power.

Applying an additional high $\alpha_{s}$ layer (5 wt $\%$ CNP/PU composite) on the top of the thermoelectric solar cell showed significant increase in the generated voltage and current (Figure 5 (c)), and the power generation increased up to about $0.210 \mathrm{~mW}$ (270\% increase). The high $\alpha_{s}$ layer absorbed the solar energy efficiently because the $\alpha_{s}$ value was 0.94 with minimal reflection. 
(a)

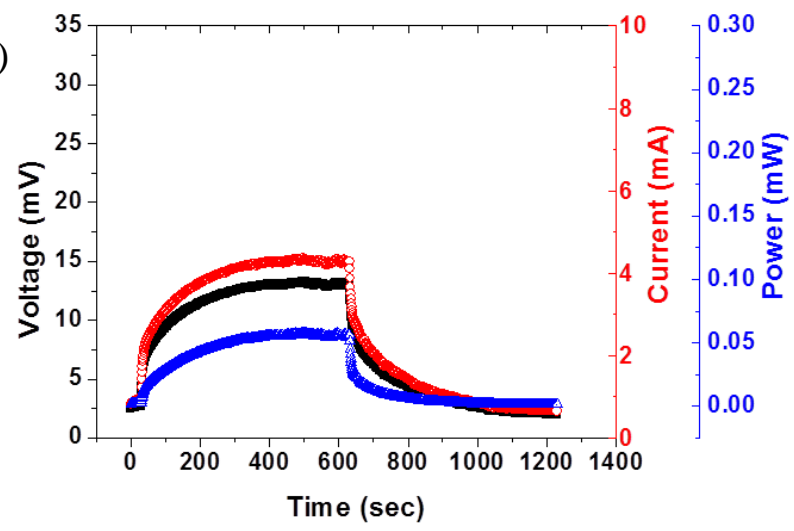

(b)

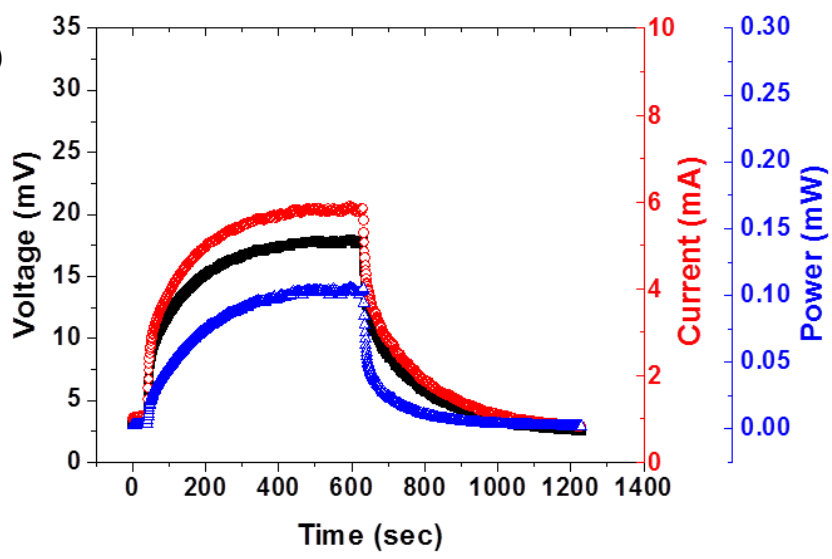

(c)

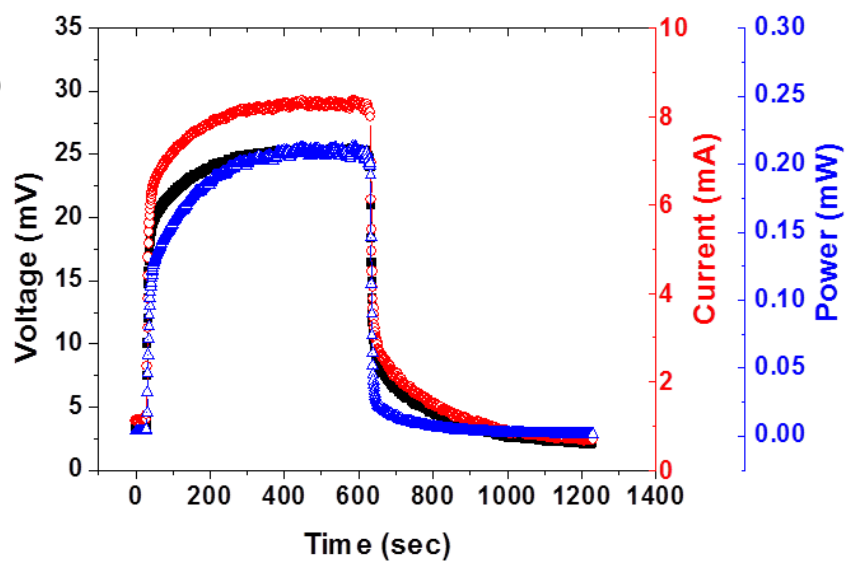

Figure 5. Generated voltage, current and power of (a) control cell without any coating, (b) with bottom high emissivity coating, and (c) with additional top high solar absorptivity coating. 
Figure 6 shows the power generation after applying different coatings and employing different assemblies of the thermoelectric solar cells. The effect with high $\varepsilon_{T}$ coating on bottom of the cell and the cell coated with additional high $\alpha_{s}$ layer on its top is shown again. Furthermore, when an additional low emissivity layer (50\% Al:ZnO/PU nanocomposite, $\varepsilon_{T}$ of about 0.3 ) was coated on the high $\alpha_{s}$ layer, the generated power is $310 \%$ higher than the control cell. The $\varepsilon_{T}$ layer helps to minimize re-radiation of solar energy and to hold absorbed solar energy on the top to show higher power generation. For further increase in holding the solar energy on the top of the thermoelectric cell, a "green house effect" was simulated by inserting an insulating spacer (polyethylene terephtalate film, $100 \mu \mathrm{m}$ thick) between the top low $\varepsilon_{T}$ layer and high $\alpha_{s}$ layer. As shown in Figure 6 , the addition of a spacer increased the power by $80 \%$ compared to the cell with no spacer, affording a 380\% increase compared to the control thermoelectric solar cell. The spacer provided a small cavity space to hold the solar thermal energy by internal reflection of secondary thermal radiation from the surface of high $\alpha_{s}$ layer. Altering the structure of the solar thermoelectric cell can further increase the solar generation power. When the thermoelectric cell was replaced with a double stack of thermoelectric cells (serial connection of two thermoelectric cells), the generated power was nearly doubled while keeping the same surface area.

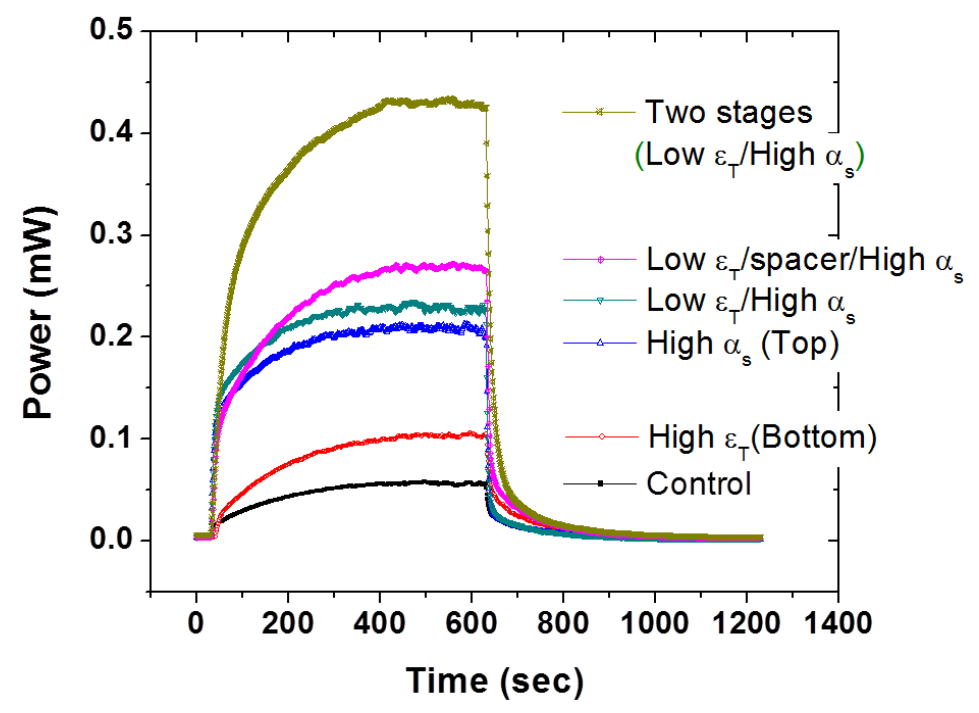

Figure 6. Generated power of thermoelectric solar cells with different coating and structures.

\section{CONCLUSIONS}

The $\alpha_{s}$ and $\varepsilon_{T}$ of polymeric materials was tailored by adding nanophase particles to polyurethane. Adding 5wt $\%$ of CNP increased the $\alpha_{s}$ and $\varepsilon_{T}$ of the composite material by factors of 47 and 2, respectively. Compared to state-of-the art high $\alpha_{S}$ and $\varepsilon_{T}$ coating of $\mathrm{CuCrO}_{\mathrm{x}}$ or $\mathrm{FeMnCuO}_{\mathrm{x}}$, the $\mathrm{CNP} / \mathrm{PU}$ polymeric nanocomposite exhibits excellent flexible mechanical properties. This tailored solar irradiation control of the materials can constitute an innovative approach for solar energy control and energy conversion, especially for a deployable solar cell structure. The effect of solar 
irradiation control of the nanocomposite on solar energy conversion was studied using thermoelectric solar cells. The thermoelectric solar cell coated with the developed solar irradiation control materials exhibited more than $380 \%$ increase in energy harvesting compared to the pristine solar cells. This new solar irradiation control material enables the fabrication of a lightweight, durable, deployable, and highly efficient solar energy harvesting film comprising exceptionally efficient solar absorbance, and passive cooling coatings plus an energy harvesting layer to enhance energy conversion.

\section{ACKNOWLEDGEMENT}

The authors appreciate Mr. David Hartman for his help in XRD characterization and the NASA Langley Research Center Creativity \& Innovation Program for support. Dr. Kang appreciates the Langley Aerospace Research Student Scholars (LARSS) program and professor H. Bao (Old Dominion University) for supporting intern students in part.

\section{REFERENCES}

[1] Seraphin, B. O., [Solar Energy Conversion: Solid-State Physics Aspects], Seraphin, B. O., Ed., [Topics in Applied Physics], Springer, New York, Vol.31 (1979).

[2] Li, P., Cai, L., Zhai, P., Tang, X., Zhang, Q., and Niino, M., "Design of a concentration solar thermoelectric generator", J. Electronic Mater. 39, 1522-1530 (2010).

[3] Miyazaki, M. and Ando, E. “Low Emissivity Film,” US Patent 5,532,062 (1996).

[4] Hamburg, I. and Granqvist, C. G., "Optical properties of transparent and heat-reflecting indium-tin-oxide films: Experimental data and theoretical analysis," Sol. En. Mater. 11 (3), 239-248 (1984).

[5] Peters, W. C., Harris, G., Miller, G. and Petro, J., "Tailoring thing-film/lacquer coatings for space applications," High Perform. Polym. 12 (1), 105-112 (2000).

[6] C. E. Holcombe, "High Emissivity Coating," US Patent 5,668,072 (1997).

[7] Xiong, J., Zheng, Z., Qin, X., Li, M., Li, H., and Wang, X., "The thermal and mechanical properties of a polyurethane/multi-walled carbon nanotube composite", Carbon 44, 2701-2707 (2006).

[8] Mauter, M. S., and Elimelech, M., "Environmetal applications of carbon-based nanomaterials", Environmental Science \& Technology 42, 5843-5859 (2008).

[9] Chung, D.D.L. "Review electrical applications of carbon materials", J. Mater. Sci. 39, 2645-2661 (2004).

[10] Mellouki, I., Bennaji, N., and Yacoubi, N. "IR characterization of graphite black-coating for cryogenic detectors", Infrared. Phys. Tech. 50, 58-62 (2007).

[11] Trovati, G., Sanches, E. A., Neto, S. C., Mascarenhas, Y. P. and Chierice, G. O., "Characterization of polyurethane resins by FTIR, TGA, and XRD”, J. Appl. Polym. Sci. 115, 263-268 (2010).

[12] Ungár, T, Gubicza, J., Ribárik, G., Pantea, C. and Zerda, T. W., "Microstructure of carbon blacks determined by Xray diffraction profile analysis", Carbon 40, 929-937 (2002). 